\title{
La gobernanza territorial y construcción de paz: entre continuidades y recomposiciones
}

\author{
Lorena Garzón Godoy*
}

La firma de los acuerdos de paz entre el Gobierno colombiano y las Fuerzas Armadas Revolucionarias de Colombia (FARC) ha puesto nuevamente en el debate público los interrogantes acerca del Gobierno a nivel territorial. Si bien la relación entre presencia del Estado en lo local y conflicto armado ha justificado distintas políticas públicas a lo largo del siglo xx, desde los planes para las zonas afectadas por la violencia bipartidista puestos en marcha por la Oficina Nacional de Rehabilitación en 1958 hasta la descentralización de la Constitución de 1991, esta no había sido incluida como elemento transversal de una negociación entre los actores del conflicto armado.

El enfoque territorial presente en el actual modelo de construcción de paz implica

[...] imponer una lógica de inclusión e integración territorial, basada en una nueva alianza entre el Estado y las comunidades para construir conjuntamente institucionalidad en el territorio. "Institucionalidad" entendida nuevamente no sólo como la presencia de unas entidades estatales, sino como el establecimiento conjunto de unas prácticas y normas que regulen la vida pública y produzcan bienestar. Una alianza en la que los programas gubernamentales, las autoridades regionales - en esto el liderazgo de alcaldes y gobernadores será fundamental $-\mathrm{y}$ las comunidades se unen para combinar la coordinación y los recursos nacionales con la fuerza y el conocimiento de la ejecución local. (Jaramillo Caro, 2014,s. p.) (énfasis de la autora)

\footnotetext{
* Candidata a doctora en Ciencia Política de la Universidad Paris X Nanterre-La Défense y magíster en Relaciones Internacionales de la Universidad Paris I Panthéon-Sorbonne. Profesora de la Facultad de Gobierno y Relaciones Internacionales de la Universidad Santo Tomás.
} 
En este sentido, la perspectiva territorial de la construcción de paz se apoya sobre dos presupuestos recurrentes en los análisis - tanto políticos, como académicos - del conflicto armado colombiano. Por una parte, las falencias del Estado colombiano en el gobierno de la totalidad del territorio nacional sería una de las causas estructurales del conflicto, el cual, además, ha provocado una profundización de la ausencia o deficiencia del Estado a nivel local. Por otra parte, la representación y acceso desigual a los derechos y servicios estatales repercute en un déficit democrático marcado por una subrepresentación institucional de algunos grupos sociales sobre otros (Pécaut, 2015).

Allende las discusiones sobre dichas explicaciones del conflicto armado, estas se convierten en el marco interpretativo a partir del cual se construyen las prácticas y políticas públicas destinadas a la implementación de los acuerdos y la construcción de paz territorial. En consecuencia, en el proceso de posconflicto la gobernanza territorial se convierte en un elemento político de análisis clave.

En primer lugar, es necesario resaltar las características múltiples y complejas de los procesos de peacebuilding, en los cuales intervienen de manera directa e indirecta diferentes actores (nacionales, locales y transnacionales), lo que crea diversas redes con recursos, normas y prácticas heterogéneas. En segundo lugar, cabe anotar que la transición de contextos de violencia extrema a procesos de pacificación y democratización suele estar imbuida de mecanismos y discursos que responden a una idea liberal de la paz, donde el empoderamiento y la participación activa de la ciudadanía juegan un papel esencial.

Entendiendo la gobernanza como un proceso de gobierno - o directivo- basado en la pérdida relativa de la autonomía del Estado como único protagonista de la acción pública a favor de un sistema de interacción entre actores de distinto tipo y nivel, es relevante cuestionar las formas y sentidos que tienen estos tipos de gobernanza en los territorios que han estado marcados por el conflicto; de esta manera, se convierten en los escenarios privilegiados de la construcción de paz. En efecto, desde una perspectiva sociohistórica del Estado, el concepto de gobernanza permite aprehender lógicas de regulación social que no entran completamente en el ideal legal-racional de la acción estatal, pero que constituyen la realidad del conflicto armado colombiano; por ende, es necesario analizar en clave del contexto actual de acercamiento al posconflicto.

Es por ello que nos detendremos someramente en la existencia de poderes intermediarios en las zonas de conflicto que realizan de facto funciones de regulación social, con el objeto de cuestionarnos sobre las transformaciones que genera el proceso de construcción de paz territorial al modificar los roles de actores presentes en los territorios y fomentar la intervención de unos nuevos, y así interpelar las prácticas de la gobernanza territorial colombiana. 


\section{Gobernar los territorios en conflicto: lecturas a partir de la gobernanza}

La duración y complejidad del conflicto armado constituye uno de los principales factores que han alimentado la discusión sobre la categorización del Estado colombiano como fallido, al no satisfacer los objetivos legal-racionales de este (Rotberg y Clapham, 2007). No obstante, esta consideración se fundamenta en una lectura institucional de la acción gubernamental, en virtud de la cual las instituciones son el centro - el actor exclusivo- de las políticas públicas. En otros términos, el Gobierno es el único que gobierna.

Desde esta lógica, el ejercicio relativo o nulo de funciones de regulación social por instituciones gubernamentales claras en amplias partes del territorio nacional constituiría un ejemplo de Estado fallido. Sin embargo, desde una perspectiva sociohistórica del Estado (Déloye, 1997), podríamos preguntarnos hasta qué punto la existencia de modos de regulación no estatales constituye una simple anomalía por solventar o modos de gobernanza en distintas escalas.

El análisis del funcionamiento estatal en los territorios del conflicto armado revela una ausencia de capacidades para regular de manera directa la convivencia social. Así, por ejemplo, un estudio de Mauricio García Villegas y Rafael Espinosa (2013) sobre las posibilidades de acceder a la justicia a nivel local demuestra que aproximadamente en la mitad del territorio las probabilidades de obtener la resolución de un asesinato son bajas, dada la ausencia de entes de investigación, enjuiciamiento y sanción. En otros términos, el acceso al ejercicio efectivo de derechos por toda la ciudadanía colombiana depende no solo de características socioeconómicas, sino también de la distribución geográfica de los servicios e instituciones gubernamentales. 
Figura 1. Desempeño integral promedio, 2005-2001

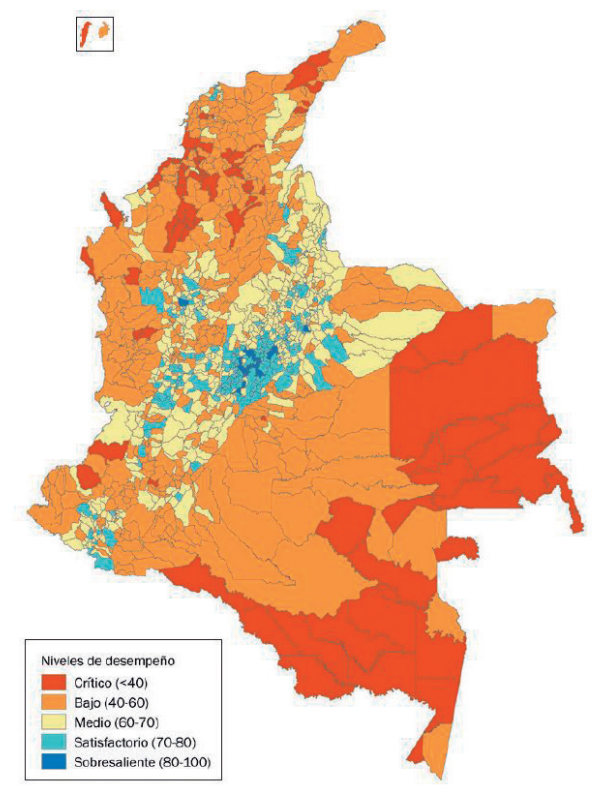

Fuente: García Villegas y Espinosa (2013).

Este ejemplo nos lleva a considerar que en Colombia coexisten diferentes escalas de gobernanza según la capacidad relativa del Estado para intervenir de manera más o menos directa en la resolución de conflictos ciudadanos. En otros términos, y retomando el concepto planteado por González y Launay-Gama (2010), Colombia posee un Estado a presencia diferenciada, cuyas capacidades de dirección y regulación varían según el nivel de integración de los territorios - y las poblaciones que allí habitan - a la vida política y económica central.

Ahora bien, la existencia de un Estado a presencia diferenciada no significa una ausencia absoluta de este; por el contrario, independientemente de los niveles de integración de las periferias con el centro, el Estado actúa de manera directa o indirecta en la regulación sociopolítica. En esta medida podemos hablar de diferentes configuraciones de gobernanza, ya que, como establece Aguilar (2010), es impensable hablar de gobernanza sin considerar en absoluto el papel del Gobierno.

Desde esta perspectiva, el análisis de las formas de gobierno en el contexto armado supone considerar los modos de articulación centro/periferia, en cuanto reveladores 
del tipo de presencia estatal con el objeto de reflexionar acerca de cómo se han establecido interacciones entre las instituciones estatales y poderes intermedios locales que participan o ejercen funciones de regulación estatal.

Habría regiones donde las instituciones estatales funcionan de manera aceptable según los cánones burocráticos y tecnocráticos de la gobernabilidad, al lado de regiones donde las instituciones estatales son prácticamente inexistentes o reducidas a la dimensión militar. También, zonas donde ellas deben negociar continuamente su funcionamiento con los poderes locales y regionales de corte gamonalicio o clientelista. (González González y Otero Bahamón, 2010, p. 31)

Retomando esta clasificación, podríamos comenzar a esbozar algunos de los elementos generales de las configuraciones de gobernanza territorial en el contexto del conflicto armado, presuponiendo que el análisis de cómo se han gobernado los territorios atravesados por el conflicto es indispensable para considerar los desafíos y las transformaciones de la construcción de paz a nivel local.

Tabla 1. Configuraciones de gobernanza en contexto de conflicto armado

\begin{tabular}{|c|c|c|}
\hline $\begin{array}{l}\text { Integración y presencia } \\
\text { directa del Estado }\end{array}$ & Mecanismos de regulación & Actores reguladores \\
\hline Alta & $\begin{array}{l}\text { Coordinación entre actores. } \\
\text { Incidencia. }\end{array}$ & $\begin{array}{l}\text { Autoridades locales. } \\
\text { Partidos Políticos. } \\
\text { Grupos sociales organizados. }\end{array}$ \\
\hline Media & $\begin{array}{l}\text { Red clientelar. } \\
\text { Coordinación con los niveles } \\
\text { nacionales. }\end{array}$ & $\begin{array}{l}\text { Autoridades locales. } \\
\text { Comisiones locales de partidos } \\
\text { políticos. } \\
\text { Líderes sociales y grupos } \\
\text { organizados. } \\
\text { Grupos armados ilegales. }\end{array}$ \\
\hline Baja & $\begin{array}{l}\text { Ordenes insurgentes: acuerdos } \\
\text { tácitos. }\end{array}$ & $\begin{array}{l}\text { Autoridades locales. } \\
\text { Fuerzas militares y de policía. } \\
\text { Líderes sociales y grupos } \\
\text { organizados. } \\
\text { Grupos armados ilegales. }\end{array}$ \\
\hline
\end{tabular}

En el caso de las zonas relativamente integradas, la forma de gobierno se basa en la negociación constante de las instituciones gubernamentales con poderes estructurados sobre redes clientelares. En amplias zonas del país, la red clientelar supone una compleja urdimbre de interdependencia: la fidelidad y adhesión electoral de la clientela es intercambiada por una serie de posiciones locales de poder ocupadas 
por los intermediarios, en retribución de "favores" materiales y simbólicos que en la mayoría de los casos se traducen en facilitar el acceso efectivo a derechos. Desde esta perspectiva, la red clientelar constituye un mecanismo de implementación cotidiana de políticas públicas, sobretodo de carácter social. La pertenencia a esta facilita el acceso a cupos escolares, diversos planes asistenciales, créditos públicos, entre otros.

En este orden de ideas, la red clientelar constituye un mecanismo de gobernanza que, si bien desde el exterior es percibido como ilegitimo e ilegal, para aquellos que están inmersos en él es una relación con lo político y lo público basada en intercambios personales de colaboración, reconocimiento y agradecimiento (Combes y Vommaro, 2015). La complejidad del caso colombiano hace que en algunas zonas estas redes se conviertan en interlocutores de la burocracia estatal, cumpliendo un papel de apoyo político e incidencia, o se institucionalizan participando de la implementación de políticas públicas.

Un ejemplo patente de ello son las políticas de descentralización llevadas a cabo a comienzos de la década de los noventa. Inicialmente, la descentralización es presentada como un mecanismo tanto de modernización de la acción estatal tendiente a hacerla más eficiente, eficaz y participativa, como de pacificación al permitir la profundización de la democracia y la llegada efectiva de los servicios estatales a las regiones más apartadas. Sin embargo, al analizar su implementación en las últimas décadas encontramos una serie de resultados paradójicos.

En distintas regiones del país, la elección por sufragio universal directo de las autoridades locales no expandió la oferta política, sino que legitimó e institucionalizó los antiguos patrones de las redes clientelares. Lo anterior no demerita el efecto de renovación de la escena política, sobre todo en las regiones más centrales.

No obstante, uno de los efectos más paradójicos del aumento de la autonomía política y fiscal de los Gobiernos municipales es la cooptación de estos por parte de protagonistas de redes clientelares, e incluso actores armados ilegales. El presupuesto municipal se convierte en una nueva fuente de financiamiento de la violencia; a su vez, la penetración en entidades municipales permite consolidar y legitimar la presencia de los grupos armados en las regiones. De facto, estos avalan la ejecución de recursos y la implementación de políticas públicas por parte de las autoridades locales electas.

Por otra parte, la apertura de la competencia política a nivel territorial exacerbó la rivalidad entre quienes encarnaban opciones políticas alternativas y aquellos que buscan mantener el statu quo de las redes clientelares tradicionales.

Estos dos elementos explican, al menos de manera parcial, la concomitancia cuantitativa del aumento de la intensidad del conflicto armado y la implementación de la descentralización (Sánchez y Chacón , 2006); resultados que coinciden y permiten explicar fenómenos como la denominada parapolítica. Las políticas de 
descentralización lograron parcialmente "modernizar" el Estado local, a fin de garantizar la construcción de paz. El fallo reside en que el clientelismo tradicional fue cooptado o substituido por actores armados ilegales que entran a participar directamente en la configuración clientelar de la gobernanza.

Este ejemplo nos lleva a considerar el rol de los actores armados como poderes que participan en el ejercicio de funciones gubernamentales. En los principales teatros del conflicto armado, los grupos armados ilegales no solo cooptaron las entidades locales, sino que han ejercido de manera directa una serie de funciones estatales de control social. Empero, un estudio detallado de las lógicas de organización de estos órdenes territoriales impuestos por los actores ilegales demuestra que no estamos ante una suplantación total del Estado, o la creación de para-Estados; por el contrario, se trata de una recomposición de los modos de gobierno donde los grupos ilegales se convierten en un actor más de una conflictiva configuración de gobernanza.

Consideremos algunos casos específicos. En un interesante estudio sobre la presencia, en primer lugar, de las FARC y, posteriormente, de las Autodefensas Unidas de Colombia (AUC) en Landázuri (municipio ubicado en el Magdalena Medio cerca a Cimitarra), María Clara Torres (2004) muestra cómo los grupos ilegales se establecieron sobre este territorio no solo a través de medios coercitivos, sino además ejerciendo funciones de intermediación entre las autoridades departamentales y la comunidad campesina. Estas intermediaciones permitieron, por ejemplo, la construcción de vías de comunicación claves para el municipio. En efecto, los actores ilegales ejercían presión sobre las autoridades locales para que obtuvieran los recursos necesarios para la elaboración de obras de infraestructura solicitadas por los campesinos. En contraposición, los actores ilegales administran justicia, seguridad y organizan el uso de las tierras, y así autoriza o regulan la inserción de economías ilegales. En este caso, los grupos armados fundan el mantenimiento de su orden territorial en la violencia y la eficiencia, tanto en la regulación directa de ciertos aspectos de la convivencia social como en la participación en la implementación de políticas públicas locales.

Además de un papel de facilitador para la ejecución de programas de Gobierno local, los grupos armados ilegales también pueden operar dentro de una lógica de repartición tácita de las funciones con las autoridades locales y estatales, sobre todo de seguridad.

La influencia de las FARC es notoria en Planadas, al punto que aún muchas decisiones de la cotidianidad se toman acudiendo a los que tienen el mando de la guerrilla en la región. No es un secreto que ante las demoras de la justicia estatal, la gente prefiere dirimir sus disputas acudiendo al comandante guerrillero que lo resuelve ya. Ocurre menos que antes cuando se recuerda que nada se perdía, no 
había robos, ni prostitución, ni drogadicción. Los guerrilleros caminaban por el pueblo a su antojo y se hacían cargo de la seguridad en la noche, en un acuerdo tácito con la Policía, que lo hacía en el día. (Millán Cruz, 2016, p. 46)

Estos acuerdos tácitos que se tejen en la cotidianidad de los territorios fueron encontrados en una investigación elaborada durante los últimos dos años en los departamentos de Huila y Caquetá. ${ }^{1}$ Muchos pobladores relatan cómo la guerrilla de las FARC ejercía funciones de administración de justicia, convivencia y regulación ambiental. Este ejercicio se realizaba, en muchas ocasiones, de manera subsidiaria a las acciones de las autoridades locales y del Estado central.

Acá uno iba donde el comandante cuando en el pueblo no le solucionaban, si la fiscalía no había resuelto nada, uno va a la fiscalía 13 [término usado para hablar del bloque de las FARC ubicado en la región del sur del Huila] y le resuelven, pero para que todo quede claro uno sabe que tiene que llevar los papeles que presentó acá en el pueblo [...] Una vez vinieron los de la CAM [Corporación Autónoma Regional del Alto Magdalena] a decir que no se podía seguir quemando las llantas, pero acá nadie hacia caso, y además donde las íbamos a poner, después de como seis meses de talleres y demás cosas, un día apareció en la plaza un escrito que el comandante mandaba a decir que o cumplíamos lo que decía la CAM o ya sabíamos que pasaba. (Comunicación personal, habitante de Isnos, Huila, julio de 2015)

En los dos casos se evidencia cómo la acción de regulación ejercida por los actores armados responde a incipientes formas de intermediación entre el Estado y la ciudadanía rural o a una suplantación subsidiaria ante las carencias de los actores públicos en el proceso de implementación de las políticas públicas.

Nos encontramos, entonces, ante una recomposición de la figura estatal forzada por la crisis que supone una situación de violencia extrema. Es por ello que podemos hablar de la emergencia de una suerte de "transacciones colusivas" (Dobry, 2009), es decir, acuerdos tácitos que establecen los actores sociales y políticos para generar un sistema de relativas certezas que posibiliten y estabilicen las prácticas sociales

1

Se trata de una investigación de tipo etnográfico realizada durante el proceso de consolidación de las mesas departamentales y municipales de víctimas en esta zona del país, mecanismos que surgen a raíz de la implementación de la Ley 1448 de 2010 y van mutando a medida que se fortalece la opción de alcanzar una salida negociada al conflicto. En consecuencia, el trabajo investigativo de terreno consistió en recorrer los principales municipios con víctimas registradas ante la Unidad de Víctimas, con el objeto de observar cuáles eran sus imaginarios frente a la acción estatal, cómo eran sus formas organizativas y cómo se relacionaban con los instrumentos derivados de un nuevo contexto jurídico-político de reconocimiento de una ciudadanía excepcional, en cuanto víctimas del conflicto armado. 
cotidianas. En este sentido, los actores institucionales locales, la Policía y Fuerzas Militares, los grupos armados ilegales y la población civil organizada establecen una serie de transacciones que permiten ejercer una regulación de la convivencia social, una forma de gobernanza concreta.

Esto no significa la ausencia de rivalidad; por el contrario, el uso de la fuerza sigue siendo el método privilegiado de control. Sin embargo, cabe resaltar la paradójica relación de los actores armados ilegales con las burocracias y normas estatales. Por un lado, encontramos una suerte de mímesis de las formas y funciones estatales por parte de los grupos ilegales; por otro, habría una exigencia de la llegada de políticas públicas que permitan el acceso a un mínimo de derechos propios al Estado de bienestar.

Esta dualidad es visible, tanto en la acción de los actores armados ilegales, como en las posiciones, discursos y prácticas de acción colectiva de la población civil en estos territorios. Constantemente, las demandas se centran en el olvido por parte del Estado que habría dejado a la población en manos de las economías y los grupos ilegales; sin embargo, la puesta en marcha de una serie de programas y planes desarrollados por burocracias específicas que se rigen por unas normas predeterminadas genera rechazos, conflictos y confusiones. Esta relación paradójica se hace patente en lo concerniente al diseño y la implementación de políticas públicas de construcción de paz.

\section{Un recorrido por la búsqueda de paz en Colombia: ¿una construcción vertical?}

El estudio de las dinámicas del conflicto armado colombiano supone considerar también los intentos de construcción de paz. Desde la década de los ochenta, los distintos Gobiernos han intentado establecer negociaciones de paz al menos con uno de los actores armados, en la mayoría de los casos con las guerrillas, y en 2005 con los grupos paramilitares. Si nos centramos en los diálogos que han desembocado en la firma efectiva de un acuerdo de paz, encontraremos ciertas convergencias y particularidades en los dispositivos puestos en marcha.

Las negociaciones de finales de los años ochenta condujeron a la desmovilización de aproximadamente siete grupos armados al margen de la ley. ${ }^{2}$ Estos acuerdos de paz preveían mecanismos de desmovilización, desarme y reincorporación (DDR), un

2 Movimiento 19 de abril (M-19), Ejército Popular de Liberación (EPL), Partido Revolucionario de los Trabajadores (PRT), Movimiento Armado Quintín Lame (MAQL), Corriente de Renovación Socialista (CRS), Milicias de Medellín, Frente Cárnica. 
indulto otorgado por ley, y la transición de movimientos armados a partidos políticos con derecho a participar en la Asamblea Nacional Constituyente de 1991.

Por otra parte, el Gobierno de Virgilio Barco implementó el denominado Plan de Rehabilitación Nacional (PRN), cuyo objetivo era fomentar la

[...] integración económica, social y política de las comunidades y estratos más pobres de la sociedad, localizados en áreas donde la presencia del Estado ha sido débil. Para ello se reorienta el gasto público hacia actividades que, en esencia, buscan elevar la calidad de vida y fortalecer la estructura productiva. (Departamento de Planeación Nacional, 1989)

Para ello, se crearon programas dirigidos al fomento de la producción, particularmente agrícola; la construcción de infraestructura vial y energética; el desarrollo de programas sociales, educativos, de atención primaria en salud, servicios públicos básicos, y promoción de la participación ciudadana mediante el fomento de organizaciones y capacitaciones laborales.

El PRN implicaba la concertación con las comunidades priorizadas de los programas por desarrollar bajo la premisa de responder con eficacidad a las necesidades reales de la población. Tras la firma de los acuerdos de desmovilización y desarme, el PRN será considerado una herramienta de reducción de la pobreza y construcción de paz.

En suma, los acuerdos de paz de la década de los noventa se basaron en la negociación de los términos de reincorporación a la vida civil de los excombatientes, sin que estos dispositivos se acompañaran de la exigencia de políticas públicas concretas de construcción de paz positiva; no obstante, la sincronía con planes destinados a cerrar las brechas con las regiones marginales y, posteriormente, con el cambio constitucional permitió la emergencia de un discurso según el cual las modificaciones normativas e institucionales de 1991 estaban destinadas a la modernización y pacificación del país.

En este orden de ideas, la descentralización, la introducción de mecanismos de participación ciudadana y el reconocimiento del carácter pluricultural de la nación colombiana son considerados vectores de paz en un contexto de desmovilización de actores armados. Sin embargo, las falencias de los consensos políticos en torno a la reducción de inequidades sociales y geográficas, la ausencia de las principales guerrillas en estos procesos de desarme y el fortalecimiento de ejércitos privados en las regiones producirán efectos paradójicos, de tal suerte que el periodo posconstituyente estará marcado por el recrudecimiento del conflicto armado (Hurtado, 2006).

Posteriormente, hacia 2004-2006 tendrá lugar la desmovilización de las AUC, fruto de una negociación inédita en la historia de Colombia, en la medida que reconocía 
un actor armado distinto a las guerrillas. El proceso se basa en la llamada Ley de Justicia y Paz, en virtud de la cual los excombatientes que contribuyeran al esclarecimiento de las violaciones a los derechos humanos cometidas durante el conflicto obtendrían una reducción de penas, la máxima posible sería de ocho años de privación de la libertad.

Nuevamente, el proceso se fundamenta en el DDR, mientras que la consecución de la paz en los territorios depende de la Política de Seguridad Democrática, la cual es planteada de manera independiente al proceso de desmovilización de las AUc. En cuanto a la participación de las comunidades, esta no es contemplada de manera explícita, lo cual acelera dinámicas de acción colectiva como la multiplicación de organizaciones de víctimas.

Siguiendo la cronología, encontramos los Acuerdos para la Terminación del Conflicto y la Construcción de una Paz Estable y Duradera (2016) firmados entre el Gobierno colombiano y las FARC. La negociación incluyó los aspectos relativos al DDR, además de una serie de puntos encaminados al diseño y la implementación de políticas públicas destinadas prioritariamente a los territorios en conflicto, a saber: desarrollo y reforma agraria, fortalecimiento de la participación política, política de sustitución de cultivos ilícitos y creación de mecanismos de justicia transicional. Se trata, entonces, de un acuerdo que trasciende los actores involucrados stricto sensu en la negociación.

Asimismo, los distintos puntos del acuerdo recalcan la necesidad de integrar a los actores sociales en el diseño y la veeduría de las políticas derivadas de lo pactado.

La participación ciudadana es el fundamento de todos los acuerdos que constituyen el Acuerdo Final. Participación en general de la sociedad en la construcción de la paz y participación en particular en la planeación, la ejecución y el seguimiento a los planes y programas en los territorios, que es además una garantía de transparencia. (Mesa de Conversaciones entre el Gobierno de Colombia y las FARC-EP, 2016, p. 7)

La invocación constante de la participación ciudadana en el marco actual de posconflicto nos lleva a poner en paralelo las dinámicas de construcción de paz que se encuentran en las distintas negociaciones concluidas satisfactoriamente. ¿Las políticas de salida del conflicto armado en Colombia responden a una lógica vertical y jerarquizada de gobierno? 
Tabla 2. Procesos de paz y lógicas de participación ciudadana

\begin{tabular}{|l|l|l|}
\hline \multicolumn{1}{|c|}{ Proceso de paz } & \multicolumn{1}{|c|}{ Temáticas negociadas } & \multicolumn{1}{c|}{$\begin{array}{c}\text { Instancias de participación } \\
\text { ciudadana }\end{array}$} \\
\hline $\begin{array}{l}\text { M-19, EPL, PRT, } \\
\text { MAQL, CRS, Milicias } \\
\text { de Medellín, Frente } \\
\text { Cárnica. }\end{array}$ & $\begin{array}{l}\text { Desmovilización, desarme y } \\
\text { reincorporación. } \\
\text { Participación política de los } \\
\text { excombatientes. }\end{array}$ & $\begin{array}{l}\text { Concordancia con la introducción } \\
\text { de mecanismos de participación } \\
\text { ciudadana constitucionales. }\end{array}$ \\
\hline AUC & $\begin{array}{l}\text { Desmovilización, desarme y } \\
\text { reincorporación. }\end{array}$ & $\begin{array}{l}\text { Comisión Nacional de Reparación y } \\
\text { Reconciliación. }\end{array}$ \\
\hline FARC & $\begin{array}{l}\text { Reforma Rural Integral. } \\
\text { Participación Política. } \\
\text { Cultivos ilícitos. } \\
\text { Justicia transicional. } \\
\text { Desmovilización, Desarme, } \\
\text { Reincorporación }\end{array}$ & $\begin{array}{l}\text { Participación de las comunidades en } \\
\text { la concertación de planes territoriales } \\
\text { como los Planes de Desarrollo con } \\
\text { Enfoque Territorial o los Planes de } \\
\text { Sustitución de Cultivos. }\end{array}$ \\
\hline
\end{tabular}

Fuente: elaboración propia a partir de datos de Mesa de Conversaciones entre el gobierno de Colombia y las FARC EP (2016), Departamento de Nacional de Planeación (DNP) (1989) y Congreso de la República de Colombia (2005).

Los acuerdos considerados mostrarían una construcción vertical. Las políticas de paz serían el fruto de una decisión del presidente de la República, que progresivamente intentará recaudar apoyos de las élites políticas durante la negociación o en el proceso de implementación. En este sentido, todo acuerdo de paz es un acuerdo entre élites políticas, incluyendo los actores desmovilizados. Estaríamos entonces ante un acto de gobierno netamente vertical.

Sin embargo, si consideramos los procesos de construcción de paz como un vector de expansión del Estado mediante la progresiva inclusión de territorios y grupos sociales en canales institucionalizados de gobierno, nos encontramos con la necesidad de restituir la complejidad de las dinámicas de implementación de este tipo de políticas. En consecuencia, pensar la construcción de paz como un proceso que, al mismo tiempo, es tributario y transforma las prácticas sociales de gobernanza presentes en los territorios supone alejarse de las visiones institucionalistas del peacebuilding.

En el caso colombiano, esto implica, además de considerar las configuraciones de gobernanza territorial que operan en el contexto de conflicto armado, contemplar las iniciativas de construcción de paz que se han desarrollado a lo largo de los años en los distintos territorios. En efecto, la historia de la búsqueda del fin de la confrontación armada está formada no solamente por los intentos dirigidos por el Gobierno central, sino que además se alimenta de un universo variopinto de iniciativas que han ido emergiendo a nivel local. 
El recrudecimiento del conflicto armado, aunado a la aparición de nuevos mecanismos de participación ciudadana, supuso una modificación de las lógicas de la acción colectiva en los territorios en conflicto. Hacia mediados de la década de los noventa, los movimientos cívicos en las zonas rurales disminuyeron a favor del surgimiento de una serie de organizaciones que acompañan las seculares solicitudes de acceso con los servicios públicos y la reforma agraria con reivindicaciones sobre la defensa de la vida y el respeto a la neutralidad de la población civil frente a los actores armados legales e ilegales (Archila, 2001).

Estos movimientos derivan en diversas iniciativas que van desde los "Laboratorios de Paz" hasta el establecimiento de mesas de negociación entre las comunidades y los distintos actores armados, incluyendo la Policía y las Fuerzas Armadas. Las comunidades comienzan a negociar, en primera instancia, la exclusión de la población civil de los enfrentamientos armados. Posteriormente, establecen prácticas organizativas participativas, con el fin de implementar canales de comunicación permanentes con las autoridades locales y nacionales. En tercer lugar, el capital organizativo que se adquiere se convierte en un recurso de movilización transnacional y en red.

Estas iniciativas locales de paz oscilan entre la resistencia civil y la construcción de redes de gobernanza desde el empoderamiento y la participación deliberativa. Si bien varían en su organización e historia, guardan características comunes, como: 1) la larga duración en el tiempo de las experiencias; 2) la construcción de alianzas con otras iniciativas regionales e internacionales; 3 ) el establecimiento de acuerdos con ONG, organismos multilaterales, fundaciones y órganos de cooperación internacional, por ejemplo, los laboratorios de paz son financiados por la Unión Europea directamente; finalmente, 5) la construcción de agendas de acción e incidencia en temáticas relacionadas con el empoderamiento de las mujeres, la defensa del medio ambiente y la disminución de las inequidades sociales (Hernández Delgado, 2009).

La multiplicación de las iniciativas de paz conlleva el surgimiento de infraestructuras de paz que crean lazos de interdependencia entre las comunidades, actores económicos y actores internacionales de distinto tipo, en la mayoría de los casos eludiendo las autoridades políticas locales y nacionales.

En consecuencia, el proceso actual de construcción de paz territorial tiene lugar en espacios donde la visión y apropiación ciudadana de la acción pública está mediada por unas complejas configuraciones de ejercicio del Gobierno donde interactúan actores 1) sociales, políticos, económicos con capitales e intereses dispares; 2) transnacionales, nacionales y locales que vehiculan distintos significados de lo que ha sido el conflicto y lo que debería ser la paz, 3) legales e ilegales que han creado formas de regulación, acuerdos y rivalidades particulares en la cotidianidad del territorio.

Ante este panorama, se hace imperativo entender los retos de la construcción de paz desde la óptica de la gobernanza, interpretándola desde dos dimensiones, a 
saber: como una nueva forma de ejercicio de gobierno o como una perspectiva para aprehender las relaciones sociales en torno a la acción estatal. En otros términos, el análisis de la gobernanza territorial obliga a contemplar tanto los dispositivos de negociación, diseño, implementación y evaluación de las políticas públicas, como las representaciones y apropiaciones que los ciudadanos en la cotidianidad hacen de ellos. A este respecto, se trata de plantear de nuevo la pregunta de Gupta (1995) sobre los procesos por los cuales la realidad del "Estado" es experimentada.

\section{Reto para la creación de una nueva gobernanza territorial: entre participación y eficacia}

A nivel territorial, la gobernanza constituye una forma de gobierno y un concepto utilizado por los actores para justificar y legitimar una visión particular de las relaciones Estado-ciudadanía. En este sentido, la idea de gobernanza dentro de los discursos y prácticas internacionales de construcción de paz constituye en sí misma un dispositivo de pacificación. Desde una perspectiva similar, el concepto de gobernanza es asimilado a la apertura de espacios de participación ciudadana, la cual puede ser vista desde una doble perspectiva: como la creación de instancias de veeduría y consulta o desde el empoderamiento y el autogobierno.

Recientemente, la literatura sobre la construcción de paz ha comenzado a focalizarse en la dimensión local, partiendo de las críticas hechas a las operaciones de paz de la ONU, sobre todo, en lo concerniente a las falencias derivadas de la descontextualización de estas. Autores como Pouligny (2004) muestran las dificultades de adaptar los procedimientos de los actores internacionales y nacionales a las realidades de los territorios afectados por violencias extremas. En consecuencia, aparecen diversas perspectivas que hablan de una paz posliberal o de un "giro a lo local", el cual se centraría en pensar los dispositivos de paz no solo como la acción dirigida y consciente de unos órganos centrales antes en disputa armada. Si bien se sigue considerando la importancia de la reforma y ampliación del Estado central para incluir nuevos actores por medio de mecanismos de concertación, el análisis se centra en la forma de incluir el máximo de actores posibles en la construcción local de espacios de reconciliación (Rudd y Lenardsson, 2015).

Desde esta lógica, la gobernanza se convierte en una garantía de buen Gobierno, por cuanto asegura el aumento de los espacios de participación en las distintas etapas de la acción estatal; multiplicación que reforzaría los esquemas de rendición de cuentas y transparencia. A su vez, el giro hacia la gobernanza de los actores internacionales de cooperación se basa en la adopción de una lectura deliberativa de la 
democracia, que se encuentra en las políticas de promoción de los derechos humanos y lucha contra la pobreza, en cuya intersección podemos situar la cuestión de la construcción de paz.

[Cuando] la victimización se generaliza, se extiende y lleva a grupos enteros a vivir en confinamiento, a retirarse de la esfera pública et cesar de esperar cualquier cosa de las instituciones. Los efectos a largo plazo de la dictadura y la violencia civil se encontrarían, entonces, en un cierto repliegue sobre la esfera privada, una disminución de la actividad asociativa, una fragmentación social. El ejercicio del poder se hace imposible en tal contexto: las violaciones de los derechos humanos afectan la posibilidad misma de vivir y actuar en colectivo. Esta degradación del "capital social" afecta a su vez el potencial de desarrollo económico: es común escuchar que los individuos modifican sus expectativas en función de aquello que estiman pueden razonablemente obtener. (Andrieu, 2012, p. 471)

Siguiendo esta línea de reflexión, la construcción de paz a nivel territorial dependería de la posibilidad de aumentar las capacidades de ejercicio de la ciudadanía. Como resultado, el enfoque territorial constituiría una reparación frente a la inequidad geográfica mediante el aumento del acceso real a los derechos. Empero, es necesario considerar cómo aumentar las capacidades de la ciudadanía mediante las políticas públicas de posconflicto.

Así, por ejemplo, la política de sustitución voluntaria de cultivos ilícitos planteada en los acuerdos de paz requiere la concertación con las comunidades. El Gobierno fomenta la creación de asociaciones de productores agrícolas, que participarían de las mesas de concertación, recolectarían la información sobre las hectáreas cultivadas de coca, propondrían un calendario de sustitución y ejercerían autocontrol en el cumplimiento por parte de la comunidad. Igualmente, en la mesa las comunidades deben establecer las necesidades de infraestructura y seguridad para garantizar la transición productiva.

Se trata de un complejo proceso de gobernanza para lograr uno de los puntos esenciales del posconflicto: la desarticulación de las economías ilegales a favor de modelos productivos legales que permitan la superación de la desigualdad rural. Sin embargo, cabe preguntarse cómo nacen las asociaciones de campesinos que no existían previamente y hasta qué punto los actores internacionales y los funcionarios de las burocracias de construcción de paz realizan una relativa reingeniería social con motivo del diseño de nuevas políticas públicas cimentadas sobre la participación ciudadana

Este último interrogante nos lleva a cuestionarnos sobre las acepciones que se le dan a la participación dentro del proceso de construcción de paz territorial. A 
la luz de los acuerdos firmados, la extensión de la participación implicaría el aumento de la representación de los territorios marginados por el conflicto, el reconocimiento de la pluralidad política, de los medios de comunicación, entre otros.

A su vez, se multiplican los espacios de concertación; sin embargo, la participación ciudadanía implica la posibilidad real de aumentar la organización y representación social por fuera de los esquemas tradicionales clientelistas, lo cual es puesto en entredicho por el asesinato y amenaza de los líderes sociales. Para el 18 de mayo de 2017 habían sido asesinados 51 líderes sociales, principalmente en los departamentos de Cauca, Antioquia, Nariño y Choco (Instituto de Estudios para el Desarrollo y la paz [Indepaz], 2017). La falta de garantías de seguridad debilita el tejido de participación que se quiere urdir, sobre todo a la luz de la historia de persecución a las alternativas políticas regionales. Diversos estudios sobre la Unión Patriótica (Centro Nacional de Memoria Histórica, 2014) muestran que los primeros asesinatos se dieron en municipios donde los candidatos alternativos habían derrotado en las urnas las redes clientelares. Esto implica pensar, según las dinámicas locales, los mecanismos para garantizar que la institucionalización de la organización y liderazgos sociales no sea percibida como una competición por eliminar.

Otro reto de la introducción de modelos de gobernanza en las políticas de posconflicto concierne la necesidad de coordinar los distintos programas que deberían ponerse en marcha de manera paralela, con el objeto de lograr una acción pública eficaz. Por ejemplo, la sustitución voluntaria de cultivos ilícitos requiere la construcción de vías terciarias y el fomento de mercados locales; a su vez, la sustitución efectiva contribuye a la disminución de la presencia de actores ilegales en los territorios, pero esta necesita un aumento en las condiciones de seguridad para los pobladores y policías que participan en el plan de sustitución voluntaria, así como un fortalecimiento de las relaciones de confianza. La coordinación, tanto horizontal, como vertical supone, entonces, uno de los mayores desafíos en el posconflicto.

Ese reto que se hace más complejo si tenemos en cuenta que la gobernanza territorial durante el posconflicto se encuentra con las dinámicas preexistentes dentro de las comunidades de organización y empoderamiento. En efecto, la emergencia en algunos territorios de iniciativas de paz fuertes con una larga tradición de negociación con los actores armados legales e ilegales, autogestión económica e incluso autogobierno, implica la interacción con comunidades organizadas desde una perspectiva de empoderamiento frente a un Estado que no ha cumplido de manera eficaz las funciones de representación y regulación social, y un mercado al cual han sido integrados parcialmente o desde la marginalidad. Los territorios con una baja presencia estatal se caracterizan por la existencia de economías de enclave que combinan elementos legales e ilegales. En palabras de Serge (2013): 
Se trata de un desarrollo regido por intereses de corto plazo, donde no hay ninguna intención de "sacrificar el desarrollo en el altar del medio ambiente" o de tener en cuenta sus efectos sociales [...] El enclave se configura como una trinchera defensiva a pesar de que su finalidad y su justificación es la transformación que supuestamente traerían sus efectos benéficos a la globalidad de la región o del país. (p. 107)

Esta economía de enclave genera un modo de producción que limita las capacidades para la reducción de las inequidades y la pobreza. En este orden de ideas, las comunidades adoptan una lógica de autogobierno basada en la defensa del territorio, lo cual deriva en la disputa acerca del uso de los recursos naturales y los modelos de desarrollo que los sustentan.

Los conflictos por el uso del territorio constituyen un reto mayor del posconflicto. Por un lado, el uso de mecanismos de participación, como las consultas previas en asuntos relativos a las políticas económicas y de desarrollo, trae a la luz las contradicciones en torno a la exhortación a una democracia más participativa y transparente.

Por otro lado, un gran número de conflictos territoriales existentes o latentes derivan de la yuxtaposición de figuras jurídicas de ordenamiento territorial especial. Los límites entre los ordenamientos de los grupos étnicos derivados de la Constitución de 1991, el fortalecimiento de las zonas de reserva campesina y de los territorios naturales por resguardar, como los bosques y las cuencas hídricas, son cada vez más difusos; hecho que representa una posible fuente de conflictos entre los actores comunitarios.

Este último punto nos obliga a considerar las asimetrías derivadas de la presencia diferenciada del Estado y las violaciones continuas a los derechos humanos en el marco del conflicto armado. En primera instancia, se encuentran brechas de inequidad social entre las regiones rurales y urbanas, y entre las regiones urbanas de le periferia y las centrales. Pero a su vez, el reconocimiento mediante distintos instrumentos jurídicos de derechos especiales a las víctimas del conflicto armado y las minorías étnicas genera una superposición de derechos difícil de armonizar.

En el caso de territorios con presencia de minorías étnicas y campesinas, la asimetría de los derechos diferenciales se convierte en un factor esencial por tener en cuenta para crear modelos efectivos de gobernanza. El departamento del Cauca es un buen ejemplo de ello, como lo muestra el estudio sobre los conflictos territoriales adelantado por Carlos Duarte (2015):

[...] el desconocimiento de los derechos de las comunidades es el conflicto central del problema agrario y de su expresión en las confrontaciones interétnicas. Esta desigualdad obedece a lo que logra, en términos de reconocimiento, la capacidad organizativa de cada actor, en los escenarios local, nacional e internacional; 
y se hace más profunda por la existencia de programas que benefician a unos por encima de otros, y por la ausencia políticas agrarias y de tierras aplicables a contextos interculturales [...] El desconocimiento de los derechos de las comunidades, frecuentemente a favor de otros grupos sociales o de terceros ajenos al territorio, produce tensiones que ponen a las comunidades en contradicción; tal es el caso, por ejemplo, con las compras de predios en territorialidades de otros sin previa consulta, con la entrega de la administración y control de la salud, y con la educación en territorios donde coexisten diversos procesos sociales. (p. 184)

Esta superposición de ordenamientos territoriales especiales obliga a crear otros espacios de coordinación y negociación. En el mismo sentido, el reconocimiento de derechos especiales a las víctimas podría ocultar las falencias para acceder a garantías de seguridad y derechos sociales.

Resumiendo, el contexto de construcción de paz genera nuevos desafíos para la materialización de modelos de gobernanza que logren cerrar las brechas de desigualdad territorial y afianzar la gobernabilidad de los territorios a partir del reconocimiento de las dinámicas existentes de organización y articulación de los distintos actores presentes en ellos.

\section{Conclusión}

Los modelos de gobernanza territorial se han ido construyendo al tenor de las lógicas del conflicto armado. Si abandonamos la idea de la ausencia del Estado como causa y consecuencia estructural del conflicto armado, a favor de un estudio detallado de las realidades concretas del ejercicio del poder en zonas de conflicto, es necesario considerar la emergencia progresiva de distintas configuraciones de gobernanza en las que coexisten y se interrelacionan las instituciones gubernamentales, actores sociales y económicos, así como los grupos ilegales.

Dichas configuraciones deben ser analizadas de manera más profunda, con el fin de anticipar y reflexionar sobre los retos propios a la construcción de paz en el contexto actual y con las herramientas pactadas. Si bien la negociación de acuerdos de paz depende de los pactos entre las élites políticas en disputa, su implementación y consolidación es fruto de la recomposición de las arenas locales de política pública. En el caso colombiano, el nivel territorial no solo es el centro de los dispositivos pactados, sino además la dimensión de expansión y redefinición del Estado.

En efecto, la dimensión local implica considerar la complejidad y diversidad de actores y sus roles: autoridades locales con relativas capacidades de acción y 
representatividad; líderes y organizaciones sociales forjadas dentro una lógica de defensa frente a la violencia; actores transnacionales que intervienen directamente en las dinámicas territoriales a través de la financiación, el acompañamiento y la verificación; actores armados ilegales que han jugado un paradójico papel de intermediación-cooptación con esferas institucionales y apropiación de funciones estatales específicas, sobre todo en lo relativo a la administración de justicia. Esas complejas redes obligan a contemplar diversos retos:

- El rol que podrían asumir dentro de los espacios de gobernanza los excombatientes.

- Los mecanismos para armonizar las disputas que surjan dentro de los espacios de participación, entendida en clave de empoderamiento o en clave de instancias consultativas.

- La coordinación entre los distintos tipos y niveles de política pública necesaria para la construcción de la paz territorial.

- Las representaciones de los actores locales sobre el Estado y la ciudadanía.

En suma, cuestionarse sobre los modelos de gobernanza territorial en un contexto de posconflicto obliga a preguntarse también sobre los procesos de recomposición de las relaciones Estado-ciudadanía. "Es en la dominación y control de áreas de frontera cultural y social - también geográfica - donde el poder estatal central se pone a prueba y se reafirma” (Jelin y Del Pino, 2003, p. 5). En el caso colombiano, es en la integración de los territorios marginados a un Estado de bienestar y no simplemente de relativo control territorial securitario donde se medirá la capacidad de expansión de la gobernabilidad mediante modelos efectivos y legítimos de gobernanza.

\section{Referencias}

Aguilar, L. (2010). Gobernanza: el nuevo proceso de gobernar. México, D. F.: Fundación Friedrich-Naumann.

Andrieu, K. (2012). La justice transitionnelle. París: Gallimard.

Archila, M. (2001). Movimientos sociales, Estado y democracia en Colombia. Bogotá: Universidad Nacional de Colombia.

Centro Nacional de Memoria Histórica. (2014). Silenciar la democracia: las masacres de Segovia y Remedios 1982-1997. Bogotá: Taurus.

Combes, H. y Vommaro, G. (2015). Sociologie du clientélisme. París: La Découverte. 
Congreso de la República de Colombia. (25 de julio de 2005). “Ley 975”, Justicia y Paz. Gaceta Nacional. Bogotá, Colombia.

Déloye, Y. (1997). Sociologie historique du politique. París: La Découverte.

Departamento Nacional de Planeación (DNP) (1989). Plan Nacional de Rehabilitación. Bogotá: autor.

Dobry, M. (2009). Sociologie des crises politiques. París: Les presses de Science Po.

Duarte, C. (2015). Desencuentros territoriales: la emergencia de los conflictos interétnicos e interculturales en el departamento del Cauca. Bogotá: Instituto Colombiano de Anmtropología e Historia [Icanh].

García Villegas, M. y Espinosa, J. (2013). El derecho al Estado: los efectos legales del apartheid institucional en Colombia. Bogotá: Dejusticia.

González González, F. y Otero Bahamón, S. (2010). La presencia diferenciada del Estado: un desafío a los conceptos de gobernabilidad y gobernanza. En F. González González y C. Launay-Gama. Gobernanza y conflicto en Colombia: interacción entre gobernantes y gobernados en un contexto violento (pp. 28-36). Bogotá, D. C.: Pontificia Universidad Javeriana.

González, F. y Launay-Gama, C. (2010). Gobernanza y conflicto en Colombia: interacción entre gobernantes y gobernado en contexto violento. Bogotá: Pontificia Universidad Javeriana.

Gupta, A. (1995). Blurred boundaries: the discourse of corruption, the culture of politics and the imaginated State. American Ethnologist, 22(2), 375-402.

Hernández Delgado, E. (2009). Resistencias para la paz en Colombia: experiencias indígenas, afrodescendientes y campesinas. Revista Paz y Conflictos, (2), 117-135.

Hurtado, M. (2006). Proceso de reforma constitucional y resolución de conflictos en Colombia: el Frente Nacional de 1957 y la Constituyente de 1991. Revista de Estudios Sociales, (23), 97-104.

Indepaz. (18 de mayo de 2017). Observatorio de conflictos y posacuerdo. Recuperado de http://www.indepaz.org.co/7504/a-la-fecha-van-51-lideres-asesinadosen-el-2017/

Jaramillo Caro, S. (13 de marzo de 2014). La paz territorial. Alto Comisionado para la $\mathrm{Paz}$. Recuperado de http://equipopazgobierno.presidencia.gov.co/prensa/ declaraciones/Paginas/paz-territorial-sergio-jaramillo-alto-comisionadopaz-proceso-paz.aspx 
Jelin, E. y Del Pino, P. (2003). Luchas locales, comunidades e identidades. Madrid: Siglo XXI.

Lefranc, S. (2007). Convertir le gran nombre: une ingénerie internationale de la pacification. Politix, 7-29.

Mesa de Conversaciones entre el gobierno de Colombia y las FARC EP. (2016). Acuerdo final para la terminación del conflicto y la construcción de una paz estable y duradera. Bogotá : Imprenta Nacional.

Millán Cruz, J. F. (2016). Planadas: la pesadilla empezó el 9 de abril. En vv.AA., Estamos mamados de la guerra: voces desde el corazón del conflicto (pp. 2359). Bogotá: Intermedio.

Pécaut, D. (2015). Una lucha armada al servicio del statu quo social y político. En Comisión Histórica del Conflicto y sus Víctimas (Ed.), Contribución al entendimiento del conflicto armado en Colombia (pp. 599-651). Bogotá: Alto Comisionado para la Paz .

Pouligny, B. (2004). Ils nous avaient promis la paix: opérations de l'ONU et populations locales. París: Presses de Science Po.

Rotberg, R. y Clapham, C. (2007). Los Estados fallidos o fracasados: un debate inconcluso y sospechoso. Bogotá: Siglo XXI.

Rudd, G. y Lenardsson, H. (2015). The local turn in peacebuilding: a literature review of effective and emancipatory local peacebuilding. Third Word Quarterly, 36(5), 825-839.

Sánchez, F. y Chacón , M. (2006). Conflicto, Estado y descentralización: del progreso social a la disputa armada por el control local, 1974-2002. En Instituto de Estudios Políticos Y relaciones Internacionales (IEPRI), Nuestra guerra sin nombre: transformaciones del conflicto en Colombia (pp. 349-402). Bogotá: Norma .

Serge, M. (2013). El mito de la ausencia del Estado: la incoporación económica de las "zonas de frontera" en Colombia. Cahiers des Amériques Latines, (71), 95-117.

Torres, M. C. (2004). El surgimiento y apuntalamiento de grupos paramilitares. Controversia, (183), 50-78. 
